\title{
Climate Regulation Of Rearing-Related Buildings - Evaluating The Factors Related To The Energy Requirement Of Heating/Cooling, And Analysis Of Alternative Solutions
}

\author{
Laszló Toth $^{1}$, Balint Horvath ${ }^{2}$, Zsolt Fulop ${ }^{3}$, Csaba Fogarassy ${ }^{4}$ \\ ${ }^{1}$ Institute of Process Engineering, Szent István University, Gödöllő, Hungary \\ toth.laszlo@gek.szie.hu \\ ${ }^{2}$ Climate Change Economics Research Centre, Szent István University, Gödöllő, Hungary \\ horvath@carbonmanagement.hu \\ ${ }^{3}$ Institute of Business Sciences, Szent István University, Gödöllö, Hungary \\ rpr1337@gmail.com \\ ${ }^{4}$ Climate Change Economics Research Centre, Szent István University, Gödöllö, Hungary \\ fogarassy.csaba@gtk.szie.hu
}

\begin{abstract}
The most notable role in the energy usage of rearing-related buildings belongs to barn climate. For animals, one of the most important climate parameter is the temperature of the barn atmosphere. This can be kept in the proper interval by either heating or cooling. Apart from the operation of technological solutions, the need for airing barns must be taken into consideration. This means there are special technical requirements for airing. Also, they can cause significant energy losses. The temperature limit of heating is mainly influenced by the technological temperature related to keeping the animal in question, its acceptable differences, the heat loss of the barn, and the airing requirement. Energy sources applicable to heating can be traditional sources (coal, oil, gas), renewable sources (solar, biomass, wind, water, or geothermal energy), or transformed energy (electricity). As these have specific operation systems, they also mean further challenges in implementing efficient energy usage. The usage of heating energy can either be optimised by the rational usage of the heating system, or machinery explicitly made for reserving energy. Sparing heating energy via recuperative heating exchange may cut costs significantly, which we also proved in this research with actual calculations. However, we have to state that the efficient usage of heat exchangers requires that the internal and external temperatures differ greatly, which has a huge impact on heat recovery performance.
\end{abstract}

Keywords: climate regulation, rearing, livestock buildings, ventilation

\section{INTRODUCTION}

We wished to create proper climate conditions for animals in rearing-related buildings, as this makes it possible to exploit genetic advantages more. Also, it has a tight connection to the health of animals. The most important factor in the energy usage of such buildings is barn climate [1]. And the most notable influence on barn climate regulation with our domestic climate is the heating of said buildings [2]. 
The energy used for heating adds a staggering amount to rearing costs, which must appear in the prices of products. Therefore, optimising heating costs is a key area for the operations of rearing lots. This also often relates to technological and economic analyses [3].

The most crucial factors (main points) which have an impact on rearing-related buildings' climate are [4]:

- meteorological attributes;

- animal species, age, body mass, physiological attributes;

- main dimensions of the building, internal structure, heating technical attributes of materials used for the building structures;

- amount of fresh air intake required for the biological processes of animals, in other words, ventilation;

One of the most important climate parameter for the animals is the temperature of the barn atmosphere [5]. If the temperature is lower than that of their skin surface, animals can expel excess heat via radiation, convection, or thermal conduction. Heat coming from radiation, convection and thermal conduction is sensed, whereas heat from evaporation is hidden (as it does not increase the temperature of the surroundings):

- Heat expulsion on the animal's body surface is supported by respiratory organs, and this is one of the most principal factors of rearing-related buildings' climate regulation.

- Via radiation, the animal's body expels heat, if the temperature of the surroundings is lower, and intakes heat if the temperature of the surroundings is higher compared to the temperature of its skin surface.

- The amount of heat exchange depends on the difference in temperature between the surrounding air and the body surface, the movement speed of air, and the size and shape of the heat exchanging surface.

- Animals can expel heat via heat conduction if the surface area of their body is in direct contact with a cooler surface. Heat exchange via heat conduction happens on the body surface area of the animal lying on the platform, which is the most important for husbandry technologies of no bedding rearing.

- The animal transfers heat to its environment via its skin and respiratory channels by evaporation. Evaporation heat expulsion depends on the size of the body surface and the intensity of air movement.

- Carbon-dioxide produced by animals must be removed from barns, and exchanged with fresh air. The metabolism of younger animals is more vigorous, which means they produce more carbon-dioxide.

- The dung and urine leaving the animals impacts the climate within the building significantly.

- Artificial ventilation and heat supplementation during winter is usually required for indoors swine and poultry rearing, whereas the important detail for free-range bovine rearing is the cooling requirement for summer. 


\section{CLIMATE REQUIREMENTS}

Inside rearing-related buildings, the feeling of heat, the thermo-connection with the environment, and the composition of the air usually determine climate requirements for animals, and they differ by animal species and age group (examples of swine rearing can be seen in Table 1 and 2).

\begin{tabular}{|c|c|c|c|c|c|c|c|c|c|c|}
\hline \multirow{2}{*}{$\begin{array}{l}\text { Cli- } \\
\text { mate } \\
\text { factor }\end{array}$} & \multicolumn{2}{|c|}{$\begin{array}{l}\text { Temperature } \\
\left({ }^{\circ} \mathrm{C}\right)\end{array}$} & \multicolumn{2}{|c|}{$\begin{array}{l}\text { Air velocity } \\
(\mathrm{m} / \mathrm{s})\end{array}$} & \multicolumn{2}{|c|}{$\begin{array}{l}\text { Relative } \\
\text { humidity }(\%)\end{array}$} & \multirow{2}{*}{\begin{tabular}{|l|}
$\mathrm{CO}_{2}$ \\
$\mathrm{ppm}$
\end{tabular}} & \multirow{2}{*}{\begin{tabular}{|l|}
$\begin{array}{l}\mathrm{H}_{2} \mathrm{~S} \\
\mathrm{ppm}\end{array}$ \\
$\begin{array}{l}\text { winter } \\
\text { summer }\end{array}$
\end{tabular}} & \multirow{2}{*}{\begin{tabular}{|l|}
$\begin{array}{l}\mathrm{NH}_{3} \\
\mathrm{ppm}\end{array}$ \\
$\begin{array}{l}\text { winter } \\
\text { summer }\end{array}$
\end{tabular}} & \multirow{2}{*}{\begin{tabular}{|l|}
$\begin{array}{l}\text { CO } \\
\text { ppm }\end{array}$ \\
$\begin{array}{l}\text { winter } \\
\text { summer }\end{array}$
\end{tabular}} \\
\hline & Winter & summer & winter & summer & winter & summer & & & & \\
\hline \multicolumn{2}{|c|}{$\begin{array}{l}\text { Recom- } \\
\text { mended }\end{array}$} & $*$ & \multicolumn{2}{|c|}{$0,1-0,25$} & \multicolumn{2}{|c|}{$60-75$} & $<3000$ & $<0,5$ & $<20$ & $<10$ \\
\hline
\end{tabular}

Table 1. Climate factors of the dropping-box [5]

*: There is a difference between the living areas of the mother swine and its offspring: the former is $\sim 20^{\circ} \mathrm{C}$ whereas the latter is $\sim 28-30^{\circ} \mathrm{C}$.

It is advantageous to have the levels of $\mathrm{CO}_{2}, \mathrm{H}_{2} \mathrm{~S} \mathrm{NH}_{3} \mathrm{CO}$ within the allowed limits of the Chart, even for closed barns.

\begin{tabular}{|c|c|c|c|c|c|c|c|c|c|}
\hline \multirow{2}{*}{ Climate factor } & \multicolumn{3}{|c|}{$\begin{array}{l}\text { Temperature } \\
\left(\mathrm{C}^{\circ}\right)\end{array}$} & \multicolumn{3}{|c|}{$\begin{array}{l}\text { Air velocity } \\
(\mathrm{m} / \mathrm{s})\end{array}$} & \multicolumn{3}{|c|}{$\begin{array}{l}\text { Relative humidity } \\
(\%)\end{array}$} \\
\hline & Winter & spring & summer & winter & spring & summer & winter & spring & summer \\
\hline Recom-mended & \multicolumn{3}{|l|}{$16-18$} & \multicolumn{3}{|c|}{$0,15-0,20$} & \multicolumn{3}{|l|}{$60-85$} \\
\hline
\end{tabular}

Table 2. Climate factors of the crammer [5]

In order to keep the minimum temperature limit of the production area in Hungary, all kept animals require heating for a shorter, or possibly longer period each year. An exception is the adult bovine: the minimum temperature limit for them is so low that it can be met by the animal's heat exchange without any heating. The length of the heating period is determined according to the temperature limit. Temperature limit can be defined as the outside temperature, under which the barn must be heated to create the temperature of the desired production area. Factors influencing the heating limit temperature and energy requirement are as follows [6]:

- desired temperature,

- allowed deviations inside the barn,

- heat loss of the barn,

- ventilation requirement.

In order to satisfy the fresh air needs of the animals using artificial ventilation, the air inside the barn area is exchanged multiple times each hour. Therefore, the energy requirement of ventilation is a decisive factor. During the heating period to decrease energy usage, it is advised to decrease the amount of ventilation within allowable levels, which is determined by the concentration of $\mathrm{CO}_{2}$. During summer, building ventilation may also have a cooling function, if the temperature does not go beyond the upper temperature limit of the production area. 
To conclude: ventilation can be used as cooling as long as the ventilated air can transport the heat produced by animals. Beyond this, cooling can be done adiabatically, and using machinery.

\section{IMPORTANCE OF VENTILATION}

The amount of ventilation can be calculated in practice with the air requirement and the number of air exchanges. Air requirement means the amount of air to be transported from the room during one unit of time, which can be defined with either volume or mass $\left(\mathrm{m}^{3} / \mathrm{s}\right.$, or $\left.\mathrm{kg} / \mathrm{s}\right)$. Proper distribution of the required volume of air can be realised via ventilation systems [7].

\section{Natural ventilation (gravitational ventilation)}

Ventilation is defined as the air exchange which exploits the movement of outside air, whereas ventilation exploiting the temperature difference is called gravitational ventilation. Air flows during ventilation due to the pressure difference between the downwind and lee-affected sides of the building. The basis of gravitational ventilation's mechanism is the difference in density resulting from temperature difference. This causes air flow through the openings created on different elevation levels, which happens when the pressure difference is higher than the pressure needed to negate air flow resistance [8]. Artificial ventilation systems are either:

$$
\begin{array}{ll}
\text { - } & \text { over-pressurised, } \\
\text { - } & \text { equalised, or } \\
- & \text { extraction-based. }
\end{array}
$$

Over-pressurised ventilation is used in places where the room to be ventilated must be protected from the outside air's impurities, or the air has to be pre-treated for ventilation (f. e. heated or cleaned). In the case of equalised ventilation, the amount of air extracted from the room matches the amount pumped in. From the perspective of investment and operation, it always has additional difference. When using an extractionbased ventilation system, the depression level of 10-30 Pa inside the ventilated room, compared to the outside. Its usage is most advantageous in places where harmful gases or smell inside the room should not escape outside [9]. Artificial ventilation can be implemented by:

- intake and exhale air corridors linked to a central ventilator, or

- individual ventilation units.

When designing the artificial ventilation for closed barns, it is important to make areas for intake and exhale processes. This is needed in order to avoid the draft effect, and proper cross-ventilation. Generally, the amount of air exchange for an animal is 60 $\mathrm{m}^{3}$ an hour during winter, and double that during summer. The usual solution applied to our domestic poultry rearing is artificial ventilation [10]. As for broiler rearing, the body mass of animals increases nearly a hundredfold during the 7-8 weeks of the rearing cycle. 
This means the amount of fresh air also has to be increased by this much. Usually, for this large amount of needed air, the ventilation system using individual ventilators is the most common solution.

\section{HEATING OF REARING BUILDINGS}

To exploit our domestic climate conditions and the genetic advantages of our animals, winter heating is required for most buildings, and it is worth to do so as well. Poultry barns (except the nest box), and dropping-boxes and post-rearing areas in swine barns must be heated. One very important consideration f.e. during swine crammers is that too high temperature decreases the feeding amount [11]. The level of requirement and amount of needed heating can be determined based on the temperature balance of the barn. The equilibrium state is when:

where:

$$
Q_{a}+Q_{f}+I_{k}+I_{s}=0,
$$

- $Q_{\text {a }}$ - heat exchange of animals,

- $Q_{\mathrm{f}}$ - heat exchange of heating,

- $\quad I_{k}$ - heat flowing through the barn's border structures,

- $I_{\mathrm{s}}^{\mathrm{k}}$ - heat leaving with ventilation.

\subsection{Heating systems of buildings}

Energy sources used for heating can be either traditional energy resources (coal, oil, gas), some kind of renewable energy resource (solar, biomass, wind, water or geothermal energy), or some kind of transformed energy (f.e. electricity). Heating systems can be differentiated between according to their heat exchangers, into categories of convective, conductive and radiating heating systems [12]. In convective heating systems, the heating machinery's heat is transported to the air via heat exchanger, while in conductive heating systems, the form of heat exchange is direct connection. In radiating heating systems (Figure 1.), the heat transportation happens directly between the heat exchanging area and the animal, without the air temperature changing.

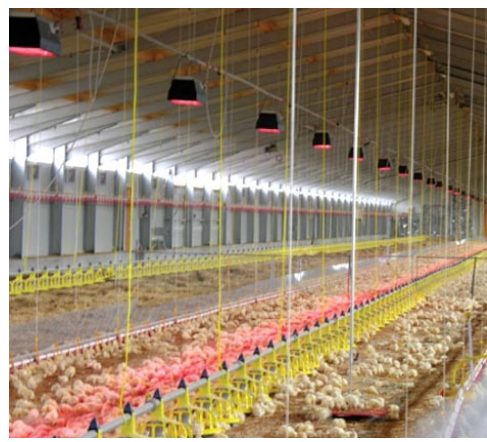

A

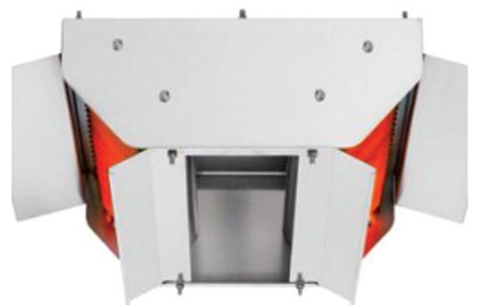

B

Figure 1. Radiating units placed on the roof (A), heating unit (B) that uses gas- or electric energy [12]

The use of radiating heating systems is currently spreading, while perhaps the most promising form of heating used for rearing is conductive heating [13]. The fact that the animal spends most of its life lying on the platform makes it possible to realise direct 
heat exchange. This conductive heat exchange offers the opportunity to significantly decrease energy usage. In rearing-related buildings, these heat exchange methods were already used as supplementary heating (swine heating pads, infra-radiators, etc.), but using them in and of themselves as heating is not completely implemented in practice, from either a technological or technical perspective.

\subsection{Evaluating factors that impact the energy requirement of heating}

The energy requirement of rearing-related buildings' heating can be determined using two factor groups [14], first of which is:

- attributes determined objectively by the animals, amount of excess heat and moisture;

- outside air temperature, and its changes in the given geographical area. and the second:

- heat insulation of buildings,

- air flow volume of ventilation,

- air temperature of the barn area.

\section{Ventilation-caused energy loss}

The ventilation air volume must be decreased as much as permissible during the heating period, from the perspective of heating energy consumption. This still has to satisfy the allowed limits of gas concentration and moisture level. In order to determine the minimal amount, a complex task is necessary. First, the gas concentration and the moisture level have to be evaluated individually. Of the permissible gas concentration levels, first, carbon-dioxide must be determined, but due to experience, we know that in some cases, other gases (ammonium, hydrogen-sulphide, methane) can also cause danger within the barn's atmosphere. Carbon-dioxide almost exclusively flows into the barn's atmosphere from the animals' breathing. Only a very slight amount comes from the micro-biological processes happening within the barn area. The absolute permissible value of moisture within the barn depends on the temperature. Experience says that in general, a wide interval is allowed, however, it is important that it does not aggregate on the building's dividing, and other structural elements. If ventilation is satisfactory, moisture gets to all animals in the barn to an optimum degree [15]. As this cannot be realised with the theoretically calculated air volume, a much higher volume of air has to be supplied. The quotient of the actual and theoretic air volume is called air excess factor. Its value is usually two or higher, which means an air mass more than two times the theoretical value must flow into the barn, in order to realise sufficient cross-ventilation. Along this mass of air, a significant amount of heat energy is also expelled during winter.

Convective heat loss depends on the internal temperature of the barns, the main dimensions of the building, and the level of heat insulation. When buildings are insulated better, they usually demand more costs, which has to be balanced via decreasing the heating energy. The required heating limit temperature for any given species of animal depends on the number of animals living in the barn, the desired internal temperature of the barn, the heat insulation of the barn building, and the level of ventilation. Usually, smaller animals need relatively more fresh air than what their comfort zone suggests. Reducing heating energy does not mostly depend on the level of heat insulation - which increases investment costs significantly - but on the realisation of satisfactory 
minimum ventilation during winter, the rigorous fine-tuning of the ventilation system (f.e. automatically), and the usage on a heat recovery system [16]. For the optimum (acceptable) heating temperature value, production results, energy consumption and their ratio have to be taken into consideration. We can define optimum heating temperature as the barn temperature usable to reach the most advantageous production.

\subsection{Conditions of using heat recovery and heat exchange units}

The consumption of heating energy can be reduced by either optimising the usage of the current heating system, or by procuring machinery explicitly made for energy conservation [17]. The energy spent for heating buildings, and the heat expelled by animals gets outside the building during winter, most of it through ventilation, and a smaller amount through the walls. Some of this energy can be rerouted into the barn building via heat recovery. Heat recovery units are basically heat exchangers, which mostly use the ventilation airflow to return the heat leaving the barn into the barn building.

Depending on the ventilation air flow receiving the heat leaving the barn either directly, or through an exchange context, we differentiate between:

- air-air heat exchangers,

- and air-context heat exchangers.

The reason for using heat recovery units can be:

- due to them decreasing the direct heating energy requirement, which makes operational costs lower, and

- due to them having the added benefit of a lower total performance heating system necessary, which makes investment costs lower.

Theoretically, any kind of heat exchanger can be used for rearing in spite of how we can mainly see surface area heat exchangers. The heat flow within recuperative heat exchangers goes through the volumes separated into the two internal areas within the machine (Figure 2). The energy flow of the heat exchange happens due to the difference in temperature. This heat exchange is fundamentally stationary and continuous [18]. Due to this, recuperative heat exchangers are of simple structure. Due to this simplicity, the volume taking part in the heat exchanger's operation can be separated perfectly.

When using recuperative heat exchangers, we may face the problem of low temperature difference between the two volumes in practice. Therefore, a suitable heat recovery performance requires the machines to have a large surface area (Figure 2).

According to their structure, surface heat exchangers are either:

- structured with sheets, or

- tube bands.

The structural material of heat exchanging surfaces is either:

- aluminium,

- glass,

- plastic, or

- stainless steel. 
Sheet heat exchangers are structurally simple, and their heat recovery effect is satisfactory (the heat recovery value is as follows: $\Phi=0,25-0,45$ ) which means that they are quite advantageous even in rearing-related buildings, but cleaning the heat exchange surfaces also has to be considered.

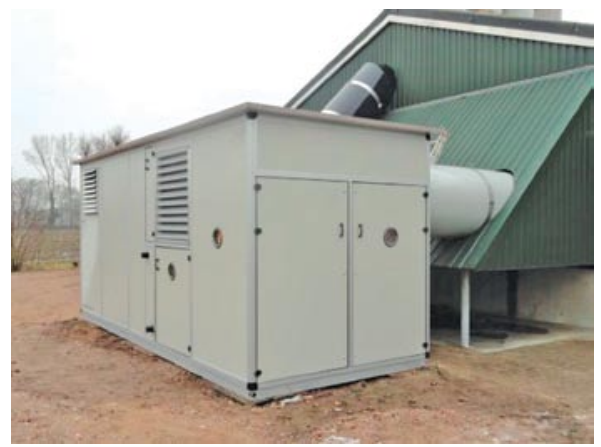

Figure 2. Large central heat recovery heat exchange unit constructed near the barn

One of the specialities of sheet heat exchangers is the ventilated building shell. The ventilated building shell in rearing can either be the wall of the barn, or the floor-space. When creating a ventilated wall or floor-space, the division structure has two layers. The air is inhaled through one of the tunnels, while it is expelled through the other. However, using the ventilated building shell, not only the partial recovery of the heat energy leaving with ventilation becomes possible, but the convective heat flow leaving through the walls can also be reduced.

\section{ANALYSIS}

During the next analysis, we used a calculation conducted for a concrete example to validate that we can save a significant amount of costs in a 1000 flock swine barn by using recuperative heat exchange. The condition of the heat exchanger working efficiently is that there is a significant difference between the internal and external temperature, which fundamentally determines the heat recovery performance. The heat exchange value of the barn's air at the intake and exhale points is represented by the values on Figure 3.

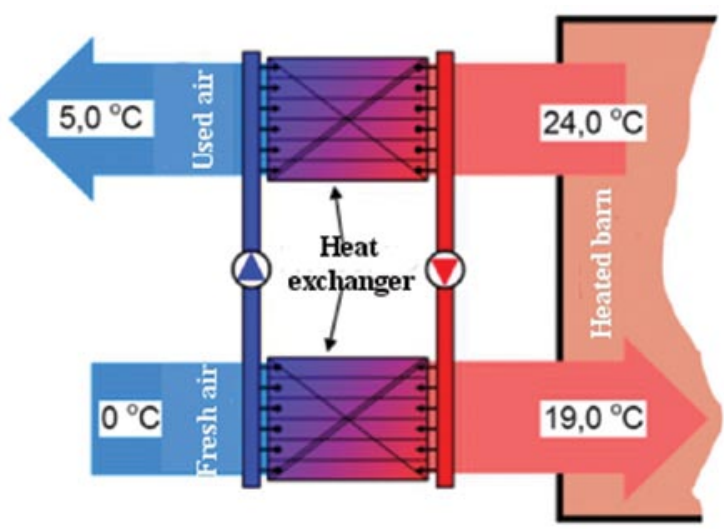

Figure 3. Characteristics of recuperative heat exchange 
Winter and summer air exchange characteristics are different for winter and summer periods, which is also influenced by heating and cooling factors. Heating and cooling, furthermore, mandatory ventilation causes energy loss, which can be reduced significantly by using recuperative heat exchangers. In our current example, the calculation is based on the air volume used for winter air exchange. The data used for the heat exchange process is summarised in Table 3 and 4.

Winter air exchange: $\mathbf{L}=\mathbf{6 0} \mathbf{~ m}^{3} / \mathbf{h}$ for each specimen (due to heating)

(Summer air exchange $\mathrm{L}=250 \mathrm{~m}^{3} / \mathrm{h}$ for each specimen, due to cooling)

\begin{tabular}{|l|c|c|c|}
\hline \multicolumn{1}{|c|}{ Name } & Air temperature (T) & Density $(\rho)$ & Specific heat (c) \\
\hline Dimension & ${ }^{\circ} \mathrm{C}$ & $\mathrm{kg} / \mathrm{m}^{3}$ & $\mathrm{~kJ} / \mathrm{kg} \mathrm{K}$ \\
\hline Fresh air (fk) & 0 & 1,293 & 1,009 \\
\hline Consumed air (Lk) & 5 & 1,270 & 1,009 \\
\hline Air intake (fn) & 19 & 1,209 & 1,013 \\
\hline Expelled air (Ln) & 24 & 1,189 & 1,013 \\
\hline
\end{tabular}

Table 3. Characteristics of air

Calculating with winter ventilation: $Q_{f-L}=\dot{m} c\left(T_{n}-T_{k}\right) \quad[\mathrm{kJ} / \mathrm{h}]$

Where:

- $\dot{m}=L \rho \quad[\mathrm{kg} / \mathrm{h}]$ (air mass flow)

- $\rho=$ air density $(\mathrm{kg} / \mathrm{m} 3)$

- $\mathrm{Qf}=$ heat performance intake $(\mathrm{kJ})$

- $\mathrm{QL}=$ heat performance expelled $(\mathrm{kJ}$

\begin{tabular}{|c|c|c|c|c|c|}
\hline & $\mathrm{L}$ & $\rho$ & $\mathrm{c}$ & $\mathrm{T}$ & Qf and QL \\
\hline & $\mathrm{m}^{3} / \mathrm{h}$ & $\mathrm{kg} / \mathrm{m}^{3}$ & $\begin{array}{c}\mathrm{kJ} / \\
\mathrm{kg} \mathrm{K}\end{array}$ & $\Delta \mathrm{K}$ & $\mathrm{kJ} / \mathrm{h}$ \\
\hline $\mathrm{Q}_{\mathrm{f}}$ & 60 & 1,251 & 1,011 & 19 & 1441,83 \\
\hline $\mathrm{Q}_{\mathrm{L}}$ & 60 & 1,2295 & 1,011 & 19 & 1417,05 \\
\hline
\end{tabular}

Table 4. Result values in the two heat exchangers for intake and expulsion $Q_{f} \cong Q_{L}$

Based on the calculation, an $\sim \mathbf{8 0} \mathbf{~} \mathbf{W W}$ heating performance can be conserved each our for $\sim 1000$ specimens of $100 \mathrm{~kg}$ swine, which is a significant reduction.

\section{CONCLUSION}

As far as technical specs go, regulation of the barn's atmosphere can be done via multiple solutions. A simple one is where an internal thermostat takes care of temperature regulation. The thermostat technically detects the internal temperature of the building, and operates structural elements aiding temperature change according to the set values. This can be done - f.e. in the case of open barns or gravitational ventilation - by closing the clappers of the appropriate hatches. The regulation can happen either directly, or by electric throughput. With more complete solutions, not only internal, but external temperature can be measured. 
By choosing pre-set values, and based on signals from the sensors, heat expelled by animals can be retaken via heat recovery, and sufficient mixing can also be done. Nowadays' most widespread solutions also have computer control. For these, even more parameters can be measured, f.e. moisture content of internal and external atmosphere, the temperatures, or the concentration of some harmful gases. Based on these, the PCU watches the pre-determined, ,selected" value, and bases the system's operations on it. The highest order of temperature control is currently the central unit, a so-called 'climate computer', which is usually part of the computer managing the entire area. Similarly to before, different parameters are also measured in these systems, and the PCU regulates and manages according to software commands. The complete climate computer can also make evaluations via software, furthermore, can even do optimisation. This way, it can choose the values which are the most economically sound for a given time, or the simplest technologically.

In order for technological tools to show their most efficient operation, the continuous monitoring of the system and the environmental factors is indispensible. A good example for this is that if the one introducing the conditions of heat exchange system usage, which clearly shows that using a recuperative heat exchanger significantly decreases the costs. However, the criteria of the heat exchange system's efficient operation is that there is a significant difference between the temperatures inside and outside, which has a huge impact on heat recovery performance. Therefore, planning for recuperative heat exchange systems is only advantageous and economically sound in case the data of the climate computer serve as a clear basis for the decision. 


\section{REFERENCES:}

[1] Veysset P., Lherm M., BÉBin D. Energy consumption, greenhouse gas emissions and economic performance assessments in French Charolais suckler cattle farms: Model-based analysis and forecasts. Agricultural Systems Volume 103 (2010), No. 1, pp. 41-50. http://dx.doi.org/10.1016/j.agsy.2009.08.005

[2] Tóтн L. Állattartási technika [Livestock farming technology], Agricultural Expertise Publisher, Budapest, 1998,788 p.

[3] Ecim-Djuric O., Topisirovic G. Energy efficiency optimization of combined ventilation systems in livestock buildings. Energy and Buildings Volume 42 (2010), No. 8, pp. 1165-1171. http://dx.doi.org/10.1016/j.enbuild.2009.10.035

[4] Cao G., Awbi H., Yao R., Fan Y., Sirén K., Kosonen R., Zhang J. A review of the performance of different ventilation and airflow distribution systems in buildings. Building and Environment Volume 73 (2014), pp. 171-186. http://dx.doi. org/10.1016/j.buildenv.2013.12.009

[5] Mösenbacher I. Optimales Stallklima: Worauf ist zu beachten? HBLFA Raumberg Raumberg-Gumpenstein (2007)

[6] Heidari MD., Omid M., Akram A. Optimization of Energy Consumption of Broiler Production Farms using Data Envelopment Analysis Approach. Modern Applied Science Volume 5 (2011), No. 3, pp. 69-78. http://dx.doi.org/10.5539/mas.v5n3p69

[7] Shen X., Zhang G., Wu W., BJerg B. Model-based control of natural ventilation in dairy buildings. Computers and Electronics in Agriculture Volume 94 (2013), pp. 47-57. http://dx.doi.org/10.1016/j.compag.2013.02.007

[8] Norton T., Grant J., Fallon R., Sun DW. Optimising the ventilation configuration of naturally ventilated livestock buildings for improved indoor environmental homogeneity. Building and Environment Volume 45 (2010), No. 4, pp. 983 995. http://dx.doi.org/10.1016/j.buildenv.2009.10.005

[9] Calvet S., Gates RS., Zhang G., Estellés F., Ogink NWM., Pedersen S., Berckmans D. Measuring gas emissions from livestock buildings: A review on uncertainty analysis and error sources. Biosystems Engineering Volume 116 (2013), No. 3, pp. 221-231. http://dx.doi.org/10.1016/j.biosystemseng.2012.11.004

[10] Faragó S., Giczi, F., Winkler D. Details to the breeding biology and hand rearing of reeves's pheasant (Syrmaticus reevesii) (Gray, 1829). Hungarian Small Game Bulletin Volume 12 (2014), pp. 105-124. http://dx.doi.org/10.17243/mavk.2014.105

[11] Park JH., Peters TM., Altmaier R., Sawvel RA. Anthony Tr. Simulation of air quality and cost to ventilate swine farrowing facilities in winter. Computers and Electronics in Agriculture Volume 98 (2013), pp. 136-145. http://dx.doi. org/10.1016/j.compag.2013.08.003

[12] Mustafa OA. Principle of low energy building design: heating, ventilation and air conditioning. International Journal of Energy, Environment and Economics Volume 22 (2014), No. 3. pp. 189-233.

[13] Renaudeau D., Collin A., Yahav S., Basilio V., Gourdine JL., Collier RJ. Adaptation to hot climate and strategies to alleviate heat stress in livestock production. Animal Volume 6 (2012), No. 5, pp. 707-728. http://dx.doi.org/10.1017/ S1751731111002448

[14] Nguyen Tlt., Hermansen JE., Mogensen L. Fossil energy and GHG saving potentials of pig farming in the EU. Energy Policy Volume 38 (2010), No. 5, pp. 2561-2571. http://dx.doi.org/10.1016/j.enpol.2009.12.051

[15] Samer M., Abuarab ME. Development of $\mathrm{CO}_{2}$ balance for estimation of ventilation rate in naturally cross-ventilated dairy barns. American Society of Agricultural and Biological Engineers Volume 57 (2014), No. 4, http://dx.doi.org/10.13031/ trans.57.10572

[16] Collier RJ., Collier L. Strategies to reduce the impact of heat and cold stress in dairy cattle facilities. Environmental Physiology of Livestock, Wiley Online Library, 2012, pp. 335. http://dx.doi.org/10.1002/9781119949091

[17] Samer M., Loebsin C., Fiedler M., Ammon C., Berg W., Sanftleben P., Brunsch R. Heat balance and tracer gas technique for airflow rates measurement and gaseous emissions quantification in naturally ventilated livestock buildings. Energy and Buildings Volume 43 (2011), No. 12, pp. 3718-3728. http://dx.doi.org/10.1016/j.enbuild.2011.10.008

[18] Wu W., Zhai J., Zhang G., Nielsen PV. Evaluation of methods for determining air exchange rate in a naturally ventilated dairy cattle building with large openings using computational fluid dynamics (CFD). Atmospheric Environment Volume 63 (2012), pp. 179-188. http://dx.doi.org/10.1016/j.atmosenv.2012.09.042 